DOI 10.15302/J-SSCAE-2020.06.006

\title{
我国海洋钻机设备发展路径研究
}

\author{
刘健 \\ （中海油研究总院有限责任公司，北京 100028）
}

\begin{abstract}
摘要: 我国海洋钻机设备的发展已取得一定成就, 浅水海洋钻机基本实现了国内自主研制, 但深水钻机设备与国外先进水平 相比仍有较大差距, 未能全面满足我国深水油田开发的需求。本文从浅水钻机、深水钻机、新型海洋钻机三方面分析了国内 外海洋钻机设备的发展现状, 总结了我国深水钻机设备技术水平发展情况、与国外先进水平的差距, 研判了深水钻机设备国 产化亟需突破的关键技术并提出了针对性建议。在进行国内外深水钻机关键技术对比分析的基础上, 研究指出我国开展海洋 钻机装备攻关应从深水钻机研制的设计、材料、工艺、检测、海上试验等方面突破。为明晰海洋钻机设备的发展路径, 研究 建议: 建立和完善海洋钻机设备的标准规范, 分类型、分阶段、分层次实施深水钻机设备的研制, 建立集成测试和海上试验 基地，加强行业间合作，以创新驱动多样化、系列化、自动化、智能化发展。
\end{abstract}

关键词：海洋钻机；深水钻机；设备研制；检测；海上试验

中图分类号：TE951 文献标识码：A

\section{Development Path of Offshore Drilling Equipment in China}

\author{
Liu Jian \\ (CNOOC Research Institute Co., Ltd., Beijing 100028, China)
}

\begin{abstract}
China has made achievements in offshore drilling equipment, and it can now develop the shallow-water drilling rigs independently. However, as far as deep-water drilling equipment is concerned, there still exists a big gap between China and the international advanced level, which inevitably hinders the deep-water oilfield development in the country. To accelerate the development of China's offshore drilling equipment, this study first analyzes the development status of the equipment in China and abroad from three aspects: shallow-water drilling machine, deep-water drilling machine, and new-type marine drilling machine; it then summarizes the development status in China and the gap between China and the international advanced level. Subsequently, it studies the key technologies for realizing the localization of the deep-water drilling equipment, and proposes corresponding countermeasures and suggestions. We propose that China should focus its efforts on making breakthroughs in the design, materials, technology, inspection, and sea test of the deep-water drilling rigs. To clarify the development path of the offshore drilling equipment, China should establish and improve the standards and specifications regarding offshore drilling rigs; develop different types of deep-water drilling equipment at different stages and by different levels; establish an integrated testing platform and a sea test base; strengthen
\end{abstract}

\footnotetext{
收稿日期 : 2020-10-09; 修回日期 : 2020-11-12

通讯作者: 刘健, 中海油研究总院有限责任公司高级工程师, 研究方向为海洋钻采装备; E-mail: liujian6@enooc.com.cn

资助项目：中国工程院咨询项目 “海洋装备发展战略研究” (2020-ZD-02); 工业和信息化部 “第七代超深水钻井平台（船）创新专项” ( 工 信部联装 [2016] 24 号); 国家科技重大专项 “深水钻完井工程技术” (2016ZX05028-001)
}

本刊网址：www.engineering.org.cn/ch/journal/sscae 
inter-industry cooperation; develop this sector in an innovation-driven mode; and promote diversified, serial, automated, and intelligent development.

Keywords: offshore drilling rig; deep-water drilling rig; development of equipment; test; sea test

\section{一、前言}

开发海洋油气资源离不开海洋钻井装备。经 过多年发展，我国海洋石油行业已经拥有坐底式钻 井平台、自升式钻井平台、半潜式钻井平台、导管 架平台模块钻机等不同类型的钻井作业装备, 形成 了系列化、差异化的海洋钻井装备型谱 [1]。目前, 我国已经具备一定的钻井平台设计、建造能力, 且 国内钻机生产厂家可以自主制造浅水平台钻机设 备。但在海洋钻机设计制造方面, 我国仍然有一些 技术需要攻关, 特别是深水钻机关键设备的设计 制造技术。由于这些技术掌握在国外少数企业手 中, 我国深水钻井系统的关键设备依赖进口, 使 得国产深水钻机的建造成本高、供货周期长、维 修保养费用高, 制约了我国深水和远海油气的开 发效率 $[2,3]$ 。

为加快推进我国海洋钻机设备的发展, 满足海 洋油气开发尤其是深远海油气开发的需求, 有必要 开展我国海洋钻机设备的发展路径研究。为此, 本 文调研国内外海洋钻机发展现状, 分析我国海洋钻 机设计建造中存在的问题, 梳理有关关键技术并提 出推进海洋钻井装备发展的对策建议。

\section{二、国外海洋钻机设备发展现状}

目前, 海上钻井作业装备主要有移动式钻井装 备、配置钻井装置的生产平台、浮式钻井生产储卸 油装置、支持船钻井装置（Tender Rig）[4 6]。海 上钻井装备的核心设备是钻机，不同类型生产平台 配置的钻机不同，因此根据作业水深不同可将海洋 钻机设备分为浅水钻机和深水钻机。具体来看, 浅 水钻机通常配置于坐底式钻井平台、自升式钻井平 台、导管架平台等浅水平台, 均采用地面防喷器; 深水钻机通常配置于半潜式钻井平台、钻井船、深 水浮式生产平台（如张力腿平台、单柱式平台）等 深水平台, 均配有隔水管, 其中张力腿平台、单柱
式平台上的钻机采用地面防喷器, 其他深水平台上 的钻机采用水下防喷器 [4]。

\section{（一）浅水钻机}

浅水钻机与陆地钻机差别不大，国内外具备浅 水钻机制造能力的厂家较多。根据提升方式不同, 浅水钻机可分为: 常规钻机、液压钻机、齿轮齿条 钻机。

\section{1. 常规钻机}

常规钻机采用传统的绞车 - 天车 - 游车提升方 式。大部分浅水钻机, 如生产平台和移动式钻井平 台配置的钻机, 均采用该提升方式。另外, 由于生 产平台配置的钻机比较简单, 生产制造常规钻机的 厂家较多。当前, 自升式钻井平台上配置的钻机大 部分由美国国民油井华高公司、挪威阿科海洋液压 公司（Aker MH）、美国卡麦隆公司生产。

2. 液压钻机

液压钻机的提升系统为液缸, 没有传统钻机的 绞车和游动系统。液压钻机在浅水平台的导管架平 台和自升式钻井平台有一定应用, 浅水用的液压钻 机大钩载荷一般较小 [7]。目前浅水平台应用的液 压钻机主要来自意大利 Drillmec 公司、意大利油井 设备国际公司 (WEI)、德国海瑞克股份公司, 其 中 Drillmec 公司和 WEI 公司生产的液压钻机提升 系统均采用单液缸和滑轮系统, 而德国海瑞克股份 公司生产的液压钻机采用双液缸且没有滑轮系统。

3. 齿轮齿条钻机

齿轮齿条钻机的提升系统为齿轮和齿条, 通 常有两种结构: 一种是齿条固定在井架上, 齿轮 箱带动顶驱沿井架的齿条移动，如美国奥格公司的 VR 系列齿轮齿条钻机、德国 Max Streicher 公司的 VDD 系列齿轮齿条钻机, 德国海瑞克股份公司的 TI-200 齿轮齿条钻机; 另一种是齿轮箱固定, 齿条 带动顶驱移动, 如挪威 TTS Sense 公司 Finder250 齿轮齿条钻机。齿轮齿条钻机在海上应用较少, 仅 在少量浅水导管架平台上应用了齿轮齿条钻机 [8]。 


\section{（二）深水钻机}

与浅水钻机不同，大部分深水钻机采用水下防 喷器和钻井隔水管, 典型的深水钻机包括布置在平 台上的钻机设备（简称地面钻机设备）和水下设备。 地面钻机设备包括: 井架及附属设备、钻台及附 属设备、提升系统、升沉补偿装置、旋转系统、高 压泥桨系统、低压泥浆输送系统、固控系统、吹 灰系统、司钻控制系统、管子处理系统 (含隔水 管运送系统)、防喷器以及采油树运送系统、井控 系统、液压动力系统、第三方设备 (如固井系统、 试油系统、燃烧臂等)。水下设备主要有隔水管系 统 (含隔水管伸缩节)、水下防喷器组（含控制系 统)。深水钻机具有载荷能力强、功率大、自动化 程度高、可靠性要求高、应用环境特殊等特点, 世界上具有深水钻机制造能力的企业数量很少。

\section{1. 地面钻机设备}

深水钻机的类型主要有交流变频钻机、瑞姆钻 机、液缸提升钻机、双面多功能塔钻机。其中, 交 流变频钻机最常用, 双面多功能塔钻机作为一种提 升系统比较特殊的钻机而应用较少。

\section{(1) 交流变频钻机}

交流变频钻机应用广泛，安装、调试、使用、 维护方便, 是当前全球应用最普遍的一种钻机。交 流变频钻机采用传统的提升系统, 钻井绞车为交流 变频绞车, 其中深水交流变频钻机必须采用天车 补偿装置或者绞车补偿装置对钻柱的升沉运动进 行补偿。深水交流变频钻机的生产企业主要是美 国国民油井华高公司、Aker MH 公司, 具有市场垄 断地位。

\section{(2) 瑞姆钻机}

瑞姆钻机是一种液压钻机, 目前已经发展到第 三代。瑞姆钻机采用升降液缸替代绞车, 同时升降 液缸带有钻柱运动补偿装置, 不需要额外配置升沉 补偿装置, 且具有液压自动送钻功能。瑞姆钻机的 井架型式大多为双井架。第一代和第二代瑞姆钻机 提升液压缸在井架两侧, 顶驱 / 大钩在中间; 第三 代瑞姆钻机井架液缸布置有较大改变, 提升液缸放 在了井架中间。

\section{(3) 液缸提升钻机}

液缸提升钻机是一种液压钻机, 采用的是固定 井架, 提升系统为多组液压缸, 液压缸在井架中间。
液缸提升钻机与第三代瑞姆钻机比较类似。

\section{（4）双面多功能塔钻机}

双面多功能塔钻机是一种专门为深水设计的新 型钻机, 钻机的井架为双作业多功能塔。双作业多 功能塔是焊接箱形梁承载结构, 塔体占地面积小, 两侧各配置一套起升系统, 主动补偿绞车放置在井 架中间, 游动系统、立根盒均在井架外侧。钻机 所有主要设备均安装在全封闭的塔体内部, 提升 系统没有桁架型井架结构, 所以大型设备可不受 传统井架 $\mathrm{V}$ 形门的作业限制而直接滑移或提升到 井口中心。

\section{2. 水下设备}

\section{(1) 隔水管}

目前具有海洋钻井隔水管制造能力的国家有美 国、挪威、法国、俄罗斯等。隔水管结构主要有法 兰式、卡篃式、卡扣式等连接形式。美国维高公司、 卡麦隆公司是世界最大的海洋钻井隔水管生产企 业, 法国石油研究院于 20 世纪 80 年代开发了卡箍 式隔水管，俄罗斯 ZAO 公司研制了铝合金隔水管。 此外，挪威阿科公司（Aker）、美国国民油井华高 公司也生产不同形式和规格的钻井隔水管。

\section{(2) 水下防喷器}

目前, 美国公司是世界主要的水下防喷器制造 商, 在技术和市场上处于垄断地位, 如卡麦隆公 司、国民油井华高公司、维高公司。水下防喷器的 主流产品为通径 $476.25 \mathrm{~mm}$ 、压力等级 $105 \mathrm{MPa}$ 、 6 个闸板的海底重型防喷器组和 MUX 控制系统, 最大工作水深超过 $3000 \mathrm{~m}$, 配套用于深水钻井船 和深水半潜式钻井平台。近期, 维高公司、卡麦 隆公司等推出压力等级为 $140 \mathrm{MPa}$ 的防喷器组, 配置 7 8 个闸板, 可用于新一代超深水半潜式钻 井平台。

深水钻机经历了从陆地到浅水再到深水的发展 过程: 从陆地钻机到浅水钻机, 主要解决了模块化、 海上盐雾腐蚀、提高自动化程度等问题; 从浅水钻 机到深水钻机, 解决了水下环境、升沉运动、自动 化程度更高等问题 [9]。陆地钻机、浅水钻机和深 水钻机的主要区别如表 1 所示。

\section{（三）新型海洋钻机}

除上述提到的海洋钻机外, 国外相关生产企业 
表 1 陆地钻机、浅水钻机和深水钻机的主要区别

\begin{tabular}{|c|c|c|c|}
\hline 特征描述 & 陆地钻机 & 浅水钻机 & 深水钻机 \\
\hline 布置情况 & 占地面积大，集成度低 & 模块化布置, 集成度高 & 平台布置紧凑 \\
\hline 移动 / 搬迁 & $\begin{array}{c}\text { 单个设备搬迁或琵装时需整体 } \\
\text { 搬迁 }\end{array}$ & 可整体移动（上下底座） & 平台移动 \\
\hline 平台运动影响 & 无 & 无 & $\begin{array}{c}\text { 对提升系统、吊机、管子处理 } \\
\text { 系统等运动设备有影响 }\end{array}$ \\
\hline 受特殊环境影响程度 & 无 & $\begin{array}{c}\text { 受高湿度高盐雾腐蚀环境、 } \\
\text { 台风影响 }\end{array}$ & $\begin{array}{c}\text { 受高湿度高盐雾腐蚀环境、台 } \\
\text { 风撤离影响更大 }\end{array}$ \\
\hline 水下环境作业装置 & 无 & 无 & 隔水管、防喷器 \\
\hline 水下控制 & 无 & 无 & 防喷器 \\
\hline 升沉运动补偿装置 & 无 & 无 & $\begin{array}{c}\text { 隔水管张力器、钻柱升沉 } \\
\text { 补偿器 }\end{array}$ \\
\hline 对作业效率要求 & 作业日费低, 对效率要求不高 & 作业日费高, 对效率要求高 & 对效率、自动化程度要求很高 \\
\hline
\end{tabular}

还在不断开展海洋钻机设备创新, 提出一些新概念 并进行新产品的研发与应用。

\section{1. 连续起下钻钻机}

连续起下钻钻机是挪威西部集团公司（West Group）研发的一种新型钻机, 技术特点是：起下 钻时, 钻机能够在钻柱升降过程中进行管柱的上卸 扣作业, 钻机能够对钻柱进行连续提升或下放, 使 钻机的起下钻速度大幅度提高, 起下钻过程中由于 压力波动引起的井内事故也大幅减少 $[10,11]$; 工作 原理是往复循环、连续上卸扣, 实现了连续起下钻 作业, 最大起下钻速度可达 $3600 \mathrm{~m} / \mathrm{h}$ 。目前该型钻 机仍处于工程样机的现场钻井试验阶段, 尚未在油 田应用推广。

\section{2. 双绞车钻机}

双绞车钻机的提升系统是在钻机的一套提升系 统中采用两个绞车, 其中一台绞车取代了传统提升 系统的死绳固定器, 将死绳端变为另一个快绳端; 采用双快绳设计, 两台绞车可同时工作, 共同提升 顶驱, 也可以锁住一个绞车, 使用单个绞车提升顶 驱。双绞车系统具有系统冗余性高、单个绞车功率 小、主动升沉补偿效率高等优点 [12]。美国国民油 井华高公司研制的带主动补偿的双绞车钻机已经在 半潜式钻井平台上得到实际应用。

\section{3. 海底钻机}

海底钻机概念在 20 世纪 90 年代被提出。 2003 年英国马里斯公司（Maris）完成了海底钻机 方案的初步可行性研究, 提出了较为详细的海底 钻机设计方案。2005 年挪威机器人钻井系统公司 (Robotic Drilling Systems) 开始研发海底钻机系统
样机, 2010 年完成试验样机试制, 代表了当前国际 海底钻机研制的最高水平。

\section{4. 獾式钻探器}

獾式钻井概念 1999 年首次被提出, 这种无钻 机钻井方式可在很大程度上解决深水、极地等特殊 复杂区域的探井所面临的难题。2011 年, 挪威成功 研发出獾式钻探器样机并进入样机试验阶段。獾式 钻探器可应用于深水作业, 大幅降低海上钻井作业 费用; 在海上可通过一艘工作船来安装钻探器, 借 助水下机器人将钻探器下放到海底的井口位置。

\section{三、我国海洋钻机设备发展现状}

目前, 我国浅水油田使用的钻井装备主要有 海洋模块钻机、坐底式钻井平台、自升式钻井平 台, 这些装备从船体设计建造到配套的船体设备、 钻机设备均已全面实现国产化, 且海洋钻机应用 情况良好。

经过多年发展, 我国半潜式钻井平台形成了作 业水深 300 3600 m 的系列船队, 在数量、作业水 深、平台配置等方面与世界先进水平接轨。通过 建造 “奋进号” “蓝鲸 1 号” 等指标先进的半潜式 钻井平台, 我国半潜式钻井平台建造水平已达到 国际先进水平 [13]。也要注意到, 国内钻机设备 生产厂家的产品集中于陆地和浅水平台用钻机设 备, 而深水钻机设备设计制造水平与国外先进水 平相比有较大差距; 国产液压钻机设备与国外先 进水平相比也有明显差距。目前, 国内导管架平 台、自升式平台等浅水平台配置的钻机设备基本 
实现了国产化，但深水平台上的钻机设备（含水下 设备) 还较多依赖进口。

我国在深水钻机使用、维护维修过程中逐渐实 现了维修国产化、备件国产化、单件部件与设备国 产化。例如, “勘探三号” 半潜式钻井平台、“南海 挑战号” 半潜式生产平台上配置的钻机有多个设备 实现了国产化。上海船厂船舶有限公司为新加坡欧 帕斯公司（Opus offshore）建造的 “老虎”（Tiger） 系列钻井船上配置的深水钻机采用了大量国产化设 备, 如井架、天车、游车、转盘、钻井绞车、泥浆 泵、隔水管吊机、猫道机、折臂吊、采油树台车、 防喷器台车、司钻房等。该系列钻井船上配置的钻 机是目前设备国产化率最高的深水钻机, 但部分关 键设备, 如隔水管系统、防喷器及控制系统、转喷 器、节流压井管汇、天车补偿系统、隔水管张力器、 顶驱、铁钻工、司钻操作椅及控制软件等均由国外 公司制造。此外, 宝鸡石油机械有限责任公司开展 了深水钻机管子处理系统、 $1536.7 \mathrm{~mm}$ 转盘、司钻 控制系统、隔水管等关键设备的研制 [14 16], 河 北华北石油荣盛机械制造有限公司研制了水下防喷 器和控制系统并建成了工程样机 $[17,18]$ 。

整体来看, 目前我国浅水钻机设备的技术水平 与国外先进水平的差距趋于减小, 但是深水钻机的 国产化率依然较低; 特别是深水钻机的部分关键设 备国内无法制造, 有些设备虽然研制出工程样机, 但没有经过现场试用或应用, 难以服务于国内外市 场。亟需进行技术突破的设备主要有: 大功率设备, 如大功率顶驱、钻井绞车; 水下设备, 如隔水管、 隔水管伸缩节、水下防喷器及控制系统; 大载荷升 沉补偿类设备, 如钻柱升沉补偿装置、隔水管张力 器; 自动化处理设备, 如管子处理系统、防喷器和 采油树运送系统; 控制系统软硬件、司钻操作系统 及控制软件; 其他关键设备, 如双井架、固井系统、 燃烧臂等。此外, 国内海洋钻机绝大部分为交流变 频钻机, 其他类型钻机很少; 深水大钩载钻机是更 适合液压钻机的形式, 而国内大功率液压钻机的设 计研制仍为空白。

\section{四、深水钻机关键技术分析}

\section{（一）国内外深水钻机关键技术对比}

国内外深水钻机技术水平的比较情况如表 2 所
示。国内在深水钻机设计、材料、工艺、检测、 现场试验、标准规范、服务等方面的技术均与国 外有一定差距, 主要表现在: 深水钻机成套设计、 水下系统设计、升沉补偿系统设计水平有待进一 步提高; 材料制造水平需要提高, 制造钻机的少 部分特殊材料 (用于液压设备、井控设备、水下 与井筒流体接触设备) 仍需进口; 产品链不齐全, 缺乏升沉补偿装置、水下防喷器等关键设备制造 能力; 企业在制造工艺、检测、试验等方面的能 力还需进一步完善; 缺乏深水钻机关键设备的企 业标准等。

\section{（二）国内深水钻机需突破的关键技术}

\section{(1) 设计与集成技术}

钻机成套设计、水下系统设计、升沉补偿系统 设计技术是深水钻机的设计难点。设计与集成技术 还包括深水钻机系统与平台接口界面设计、深水钻 机不同系统之间接口界面设计、整合钻机各个设备 形成一套完整钻机的系统等。

\section{(2) 特种材料}

特种材料包括有特殊性能要求的金属材料（耐 高温、耐腐蚀、耐冲蚀的合金)、耐高温橡胶材料 等, 如制造水下防喷器的材料、生产液压密封元 件的材料。

（3）特殊加工工艺和热处理工艺

具体包括制造水下防喷器大型锻件的锻造和热 处理工艺、液压元件内流道的精密加工工艺、大型 液压缸的精密加工和表面热处理工艺等。

（4）制造过程中的检测

深水钻机设备在制造过程中主要开展以下检 测: 材料鉴定测试 (如抗腐蚀性、抗高低温、拉伸 试验、冲击试验、弯曲试验、硬度试验等), 焊接 工艺和性能鉴定测试, 质量控制过程试验和无损检 测, 其他基础测试 (如化学 / 晶相分析、蠕变试验、 非金属材料试验、牺牲阳极测试、涂层测试、防火 测试等)。

（5）集成测试和试验验证

深水钻机设备需开展部件、设备或系统的 FAT 和 EFAT, 部分深水钻机设备 (如水下防喷器组) 应开展 SIT, 对新研制设备或改型设备还应进行可 靠性试验验证。不同设备的测试验证内容不同, 如 水下闸板防喷器的 FAT 内容主要包括：密封性试 
表 2 深水钻机设备关键技术的国内外水平比较

\begin{tabular}{|c|c|c|c|}
\hline \multicolumn{2}{|c|}{ 深水钻机关键技术 } & 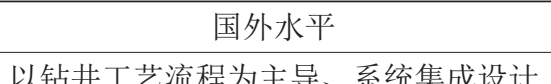 & 国内水平 \\
\hline 设计 & $\begin{array}{c}\text { 成套 } \\
\text { 单件设备 }\end{array}$ & $\begin{array}{c}\text { 以钻井工艺流程为主导、系统集成设计 } \\
\text { 全系列设计成熟 }\end{array}$ & $\begin{array}{c}\text { 模仿为主, 成套设计能力有差距 } \\
\text { 水下系统设计、升沉补偿系统设计能力 } \\
\text { 不足 }\end{array}$ \\
\hline & 新产品 & 新产品设计能力强 & 无 \\
\hline \multirow[t]{3}{*}{ 材料 } & 常规金属材料 & 成熟 & 成熟 \\
\hline & 特殊合金 & 成熟 & $\begin{array}{c}\text { 耐高温、耐腐蚀、耐冲蚀的合金等需要 } \\
\text { (如液压设备、井控设备、水下的流体接触设备的材料) } \\
\text { 筒) }\end{array}$ \\
\hline & 特殊非金属材料 & 成熟 & 部分材料需进口 \\
\hline 工艺 & 加工工艺 & 成熟 & $\begin{array}{c}\text { 成熟, 但金属密封、特殊热处理工艺仍 } \\
\text { 有差距 }\end{array}$ \\
\hline \multirow[t]{2}{*}{ 检测 } & 设备和工艺 & 检测设备齐全、工艺完善 & 部分检测设备缺乏 \\
\hline & 技术体系 & $\begin{array}{l}\text { 材料、鉴定、工厂测试 (FAT) 、扩展 } \\
\text { 工厂测试 (EFAT)、现场测试 (SIT) }\end{array}$ & 体系化不完善 \\
\hline 现场试验 & 海试 & 新产品经过海试 & 缺少海试环节 \\
\hline \multirow[t]{2}{*}{ 标准规范 } & 行业性标准规范 & $\begin{array}{c}\text { 美国石油学会（API）、国际标准化 } \\
\text { 组织（ISOO，挪威船级社 (DNV) } \\
\text { 标准, 覆盖各种标准 }\end{array}$ & $\begin{array}{c}\text { 行业标准和国际标准较齐全, 但是部 } \\
\text { 分关键设备缺少标准, 部分为采用国 } \\
\text { 际标准 }\end{array}$ \\
\hline & 厂家标准规范 & 各个厂家均有更严格的企业标准 & 针对深水钻机的厂家规范较少 \\
\hline \multirow[t]{2}{*}{ 服务能力 } & 硬件服务能力 & 安装、调试、维修、维护服务能力 & 缺乏 \\
\hline & 软件服务能力 & 软件开发、调试、升级能力 & 缺乏 \\
\hline \multirow[t]{5}{*}{ 其他 } & 系统集成能力 & 具有很强的集成能力 & 缺少集成能力 \\
\hline & 设备自动化控制 & 软硬件体系完善 & 开发测试体系缺乏 \\
\hline & 设备重量控制 & 体积小、重量轻 & 体积大、重量大 \\
\hline & 质量控制 & 质量控制严谨, 产品可靠度高 & 可靠性一般 \\
\hline & 创新能力 & 原创能力强 & $\begin{array}{c}\text { 具有单个设备 / 装置的创新、集成创 } \\
\text { 新能力 } \\
\end{array}$ \\
\hline
\end{tabular}

验、疲劳试验、承压起下钻寿命试验、剪切试验、 悬挂试验、闸板拆装试验、闸板锁紧试验。SIT 测 试目的是在场地模拟海上的实际安装作业步骤及使 用, 验证钻机设备的配合界面的匹配性、安装程序 有效性及功能的完整性。目前国内在深水钻机设备 测试方面还未形成系统的测试技术、测试流程和测 试设备。

（6）首制设备的海上试验

在推进深水钻机关键设备研制的过程中，有 大量钻机设备是国内厂家的首制设备。对首制钻 机设备, 虽然开展了材料测试、性能鉴定测试、 FAT、SIT 等，但是这些测试不能完全证实设备的 可靠性, 因此对重要设备, 还要在海上实际工况 下进行试验或试用（如国外研发双梯度钻井系统 过程中进行了长时间的海上试验)，以确保设备的
功能、可靠性满足实际作业要求。为此, 需明确 各个设备的海试内容、作业程序、海试大纲、结 果评估方法等。

\section{（7）深水液压钻机}

除以上关键技术外, 深水液压钻机还需突破大 载荷高速液压缸、液压缸升沉补偿系统、大流量高 精度液压阀件、大功率液压泵站等关键液压设备研 制的关键技术。

\section{五、对策建议}

\section{（一）建立和完善标准规范}

标准规范的完善程度可以反映行业的发展水 平。目前, 我国深水钻机技术水平不高, 针对深水 钻机特有的设备, 如水下防喷器、隔水管、车升沉 
补偿装置、主动升沉补偿绞车、隔水管张力器等制 定的标准规范基本是对 API 或 ISO 标准的采标。为 扎实推进深水钻机技术水平的发展, 我国亟需推进 自主制定深水钻机标准规范工作。通过标准规范的 制定与完善, 总结已有成熟经验, 促进建造水平的 提高, 形成自有的设计、制造、检验、使用体系。 在针对设备制定的标准规范中, 设计标准规范、材 料标准规范、检测标准规范均是重点。此外, 对于 首制产品, 还应建立海上试验、海上应用的标准规 范, 推进设备的国产化进程。

\section{（二）分类型、分阶段、分层次实施深水钻机设备 的国产化}

深水钻机设备的国内技术成熟度不同, 应开展 国产化技术成熟度分析，划分设备的国产化阶段。 相关的国产化阶段可概括为三类: 第一类, 暂不开 展国产化应用, 需要开展海上试验、工程样机建造、 工程样机测试、原理样机研发等; 第二类, 设备可 国产化 (需测试), 需要开展海上试验或现场试用; 第三类, 可国产化应用, 直接进行工程应用, 开展 EFAT 或 SIT 后应用。由于深水钻机设备的重要性 不同、设备失效可能性及失效后果也不同, 因此需 要进行评估分析, 宜根据重要性等级、国产化阶段、 技术难度、失效风险等级等因素来划分钻机设备类 型, 针对不同类型设备采用不同的国产化策略。例 如, 对重要设备、大功率设备或应用环境恶劣的设 备, 应开展大量试验, 确保可靠性; 对全新首制设 备, 应从原理样机、试验样机、工程样机各个阶段 开展研发。此外, 不是所有的深水钻机设备都需要 开展海上试验, 而应根据深水钻机设备的重要性和 风险分级来确定哪些设备需要进行海上试验。

\section{（三）建立集成测试和海上试验基地}

开展严格的测试是深水钻机设备国产化的关键 因素。在深水钻机设备制造过程中, 测试和试验 环节非常重要, 特别是隔水管、水下防喷器组等 水下设备, 因其作业环境恶劣、承受复杂载荷并 且对可靠性要求很高, 必须严格进行测试来保证 产品质量。针对一些测试设备分布分散、利用率 不高等问题, 建议在国家层面进行规划, 整合国 内现有测试资源, 建立集成测试基地, 开展国产
化设备的集成测试，充分提高测试装备的利用率。 另外, 国产化首制设备经过海上试验, 可以更容 易得到用户认可, 也可以在海上试验过程中发现 问题并进行改进。鉴于海上试验费用高、企业难 以找到配套设施和海试场地, 建议在国家层面的 支持和统筹下, 由相关企业和用户联合搭建专用 的海上试验平台, 开放控制系统的用户接口, 专 门用于国产化设备的海上试验。

\section{（四）开展新研制设备应用的作业风险评估}

国内新研制的深水钻机设备若要投入试用或者 进行实际应用, 必须在应用前开展作业过程中的风 险分析, 确定风险点, 制定风险应急预案。辨识深 水钻机设备在钻井作业过程中可能存在的各种风险 因素, 开展风险评估, 依据风险可接受程度来判断 风险水平, 针对性制定风险控制措施, 从而使国产 化深水钻机设备的作业风险下降到合理可接受的水 平。对于国内深水钻井设备的作业风险评估工作, 建议由具有相关资质和丰富经验的机构 (如国内外 船级社) 来承担。

\section{（五）加强行业间的广泛合作}

我国生产海洋钻机设备的企业数量不多, 且不 可能一家企业独立解决所有关键问题。建议钻机生 产企业加强与相关行业的广泛合作, 为海洋钻机的 设计、材料、精加工、热处理、液压元器件、控制 元件、软件开发等关键技术突破寻求协作支持, 尽 快形成完整的产品制造链。必要时可开展全球合作 研究, 通过全球采购完成整套钻机产品的研发与制 造。目前, 我国已经出台相关制度为重大设备研制 和应用创造条件, 为海洋钻机国产化提供支持, 如 重大技术装备保险机制、建立中国海工联盟等。今 后, 相关海洋钻机制造企业、设备应用企业、承担 技术攻关的高等院校和科研院所需加强合作, 共同 建立标准规范体系并持续完善, 打造高水平的研究、 设计、建造人才队伍, 形成 “产学研用” 相结合的 自主研发创新体系, 快速推进海洋钻机设备的国产 化发展进程。

\section{（六）创新驱动}

深水钻机设备市场长期被来自美国、挪威等国 
家的少数企业垄断, 我国通过常规技术发展路径实 现超越的难度较大, 亟需通过技术创新打破垄断并 进入全球深水钻机市场。因此, 应注重和加强技术 创新，针对中国南海海域特点开展深水钻机的国产 化工作, 形成新产品以打破国外企业的垄断地位。 建议率先开展单个设备或工具的原始创新, 如我国 首创的隔水管防台软悬挂装置 [19]; 持续开展成套 钻机的集成创新, 如国内已开展的双井架连续起下 钻钻机设计。通过创新驱动, 稳步推进并拓宽深水 钻机新产品在海洋油气开发的应用。

\section{（七）多样化、系列化、自动化、智能化发展}

我国海洋钻机产品型谱比较单一，未来应朝 着多样化和系列化方向发展，满足不同类型的需 求。例如, 制造轻型液压钻机满足浅水小型平台 的钻修井需求, 发展大钩载钻机满足深水和超深 水钻井的需求。自动化、智能化是未来工业的发 展方向, 应加快开展海洋钻机专用钻台机械手、 铁钻工、动力猫道、自动排管机、井口自动化工 具等设备的研制, 将自动送钻系统、数据采集、 闭环控制、图像识别、远程监控、故障识别等技 术整合进入司钻控制系统, 实现海洋钻机操作的 自动化和智能化。

\section{参考文献}

[1] 朱江. 铸海一一国海洋钻井装备飞跃发展 30 年 [M]. 北京: 中 国科技出版传媒股份有限公司, 2015.

Zhu J. Casting the sea: 30 years of rapid development of China's offshore drilling equipment [M]. Beijing: China Science Publishing \& Media Ltd., 2015.

[2] 刘峰. 深水钻井特大型装备国产化分析及建议 [J]. 石油天然气 学报, 2010, 32(4): 402-405.

Liu F. Analysis and suggestions on localization of large deepwater drilling equipment [J]. Journal of Oil and Gas Technology, 2010, 32(4): 402-405.

[3] 王定亚, 朱安达. 海洋石油装备现状分析与国产化发展方向 [J]. 石油机械, 2014, 42(3): 33-37

Wang D Y, Zhu A D. Current situation of offshore petroleum equipment and development orientation of localization $[\mathrm{J}]$. China Petroleum Machinery, 2014, 42(3): 33-37.

[4] 刘健. 深水钻井装备国产化关键问题分析 [C]. 珠海: 海洋强国 发展战略论坛, 2019.

Liu J. Analysis on key problems of localization deepwater drilling equipment $[\mathrm{C}]$. Zhuhai: The Forum on the Development Strategy of Maritime Power, 2019.

[5]李迅科, 刘健, 殷志明. 我国深水油气装备现状及发展趋势浅谈
[C]. 北京: 海洋工程装备产业政策及标准化建设交流会, 2015.

Li X K, Liu J, Yin Z M. A brief discussion on the present situation and development trend of deepwater oil and gas equipment in China [C]. Beijing: Exchange Meeting on Policy and Standardization Construction of Offshore Engineering Equipment Industry, 2015.

[6] Howard H, Hampshire K, Moore J, et al. Azurite field development: Lessons learned from industry's first PDPSO [C]. Houston: Offshore Technology Conference, 2010.

[7] 廖国敏, 周雄, 徐坤, 等. 海洋液压钻机研究综述与展望 [J]. 石 油矿场机械, 2016, 45(4): 12-15.

Liao G M, Zhou X, Xu K, et al. Study review and prospect of offshore hydraulic drilling rig. [J]. Oil Field Equipment, 2016, 45(4): $12-15$.

[8] 杨洁, 徐勇, 蔡俊, 等. 国内外齿条齿轮钻机现状 [J]. 机械工程 师, 2015 (1): 39-41.

Yang J, Xu Y, Cai J, et al. Status quo of rack and pinion drill at home and abroad [J]. Mechanical Engineer, 2015 (1): 39-41.

[9] 侯福祥, 张永红, 王辉, 等. 深水钻井关键装备现状与选择 [J]. 石 油矿场机械, 2009, 38(10): 1-4.

Hou F X, Zhang Y H, Wang H, et al. Status and selection of key equipment for deep water drilling [J]. Oil Field Equipment, 2009, 38(10): $1-4$.

[10] Grinrod Mads. Contineous motion rig: A step change in drilling equipment, mads grinrod [C]. New Orlean: IADC/SPE Drilling Conference and Exhibition, 2010.

[11] 王定亚, 叶强, 张强, 等. $7000 \mathrm{~m}$ 连续起下钻及连续循环智能钻 机技术研究 [J]. 石油机械, 2017, 45(6): 1-4.

Wang D Y, Ye Q, Zhang Q, et al. 7000 m continuous motion intelligent drilling rig [J]. China Petroleum Machinery, 2017, 45(6): $1-4$.

[12] Fivelstad O, Verhoef R, Ogg T, et al. Dual active heave drilling drawworks: From concept to operational life [C]. Fort Wort: IADC/SPE Drilling Conference and Exhibition, 2014.

[13] 洪术华, 宋雍, 叶景波, 等. 海洋工程发展现状与跨越发展战略 [J]. 船舶工程, 2019, 41(S2): 264-268.

Hong S H, Song Y, Ye J B, et al. The current situation of marine engineering development and the strategy of leapfrog development [J]. Ship Engineering, 2019, 41(S2): 264-268.

[14] 王进全, 王定亚. 国外海洋钻井隔水管与国产化研究建议 [J]. 石 油机械, 2009, 37(9): 147-150.

Wang J Q, Wang D Y. Research proposals for overseas marine drilling riser and localization [J]. China Petroleum Machinery, 2009, 37(9): 147-150.

[15] 吕拴明, 覃建, 张凯, 等. 海洋钻井隔水管单根制造技术研究 [J]. 石油矿场机械, 2016, 45(6): 76-80.

Lyu S M, Qin J, Zhang K, et al. Manufacturing technique research of offshore drilling riser single [J]. Oil Field Equipment, 2016, 45(6): 76-80.

[16] 王维旭, 杨秀菊, 任永强, 等. 半潜式钻井平台深水钻井系统的 研究与设计 [J]. 机械制造, 2018, 56(10): 41-44.

Wang W X, Yang X J, Ren Y Q, et al. Research and design of deepwater drilling system for semi-submersible drilling platform [J]. Machinery, 2018, 56(10): 41-44. 
[17] 侯国庆, 许宏奇, 粟京, 等. 深水防喷器系统FMECA分析 [J]. 石 油矿场机械, 2014, 43(8): 52-57.

Hou G Q, Xu H Q, Su J, et al. FMECA analysis of deepwater subsea BOP system [J]. Oil Field Equipment, 2014, 43(8): 52-57.

[18] 曹树杰, 王冬石, 温纪宏, 等. 深水防喷器系统可靠性分析 [J]. 海 洋工程装备与技术, 2017, 4(1): 1-6.

Cao S J, Wang D S, Wen J H, et al. Reliability analysis for deepwater BOP system [J]. Ocean Engineering Equipment and Technology, 2017, 4(1): 1-6.

[19] 盛磊祥, 许亮斌, 刘健, 等. 新型深水钻井隔水管悬挂系统设计 [J]. 海洋工程, 2019, 37(5): 99-106.

Sheng L X, Xu L B, Liu J, et al. A new conceptual design for suspending drilling riser system [J]. The Ocean Engineering, 2019, 37(5): 99-106. 